\title{
Analytical Solution for Stress and Displacement after X-Section Cast-in-Place Pile Installation
}

\author{
Hang Zhou, Han Long Liu, Gangqiang Kong, and Zhaohu Cao \\ College of Civil and Transportation Engineering, Hohai University, Nanjing, Jiangsu 210098, China \\ Correspondence should be addressed to Gangqiang Kong; gqkong1@163.com
}

Received 13 October 2013; Accepted 1 November 2013

Academic Editor: Yuji Liu

Copyright (C) 2013 Hang Zhou et al. This is an open access article distributed under the Creative Commons Attribution License, which permits unrestricted use, distribution, and reproduction in any medium, provided the original work is properly cited.

$\mathrm{X}$-section cast-in-place (referred to as XCC) pile, which is one of new pile types developed by Hohai University, is widely used for pile foundation and pile-supported embankment over soft ground in China. However, little research has been carried out on this new type pile, especially the surrounding soil disturbance under XCC pile installation. This paper presents an analytical solution for estimating the horizontal stress and displacement of surrounding soil of XCC pile after XCC pile installation. The reliability and accuracy of the present solution are verified by comparing them with the field test results. Then, parametric studies, such as outsourcing diameter $(a)$, open arc distance $(b)$, open arc angle $(\theta)$, the undrained strength $\left(S_{u}\right)$, the limit pile cavity pressure $\left(P_{\text {lim }}\right)$, and the radius of the plastic zone $\left(R_{p}\right)$, are discussed for the practice engineering design. The results show that the stress and displacement distributions of surrounding soil calculated by this paper are in agreement with field test results.

\section{Introduction}

Driven cast-in-place pile, which belongs to displacement pile type, is widely used in China [1]. Surrounding environment will be influenced by displacement pile installation obviously. If handed improperly, it will cause the uplift or subsidence of the ground and even engineering accidents. Therefore, it is essential to predict the horizontal stress and displacement induced by the pile installation. Various approaches have been used to study the horizontal stress and displacement including cavity expansion method (CEM) [2-7], strain path method (SPM) [8], and modified SPM (SSPM) $[9,10]$. CEM was proposed by Bishop et al. firstly and was used to solve the metal indentation problems. Subsequently, CEM was applied to solve the geotechnical problems such as the pile penetration and the bearing capacity of deep foundation (Vesic (1972)) [2]. In this method, a cylindrical (or spherical) cavity of zero radius was assumed in soil located near the tip of pile. The pressure around the tip of a pile to cause penetration is the limit pressure required to expand the cavity from an initial radius to the radius of the pile. The limit pressure for the expansion of the cavity is a function of the shear strength and compressibility of the soil. Based on the fluid mechanics, the strain path method (SPM) was proposed by Baligh (1985) [8] and modified by Sagaseta et al. (1997) [9]. The process of the pile penetration is assumed as a steady flow of soil around the pile rather than an expansion of a cavity in soil. Although the CEM and SPM are simple and easy to use, they can only solve the axisymmetric or spherical symmetric problem. However, for the special shaped pile installation, such as XCC pile, rectangular cross-section pile (barrette), they are unavailable.

As a new immersed tube pile, XCC pile is developed by Hohai University, China [11]. The pile is formed by installation of the $\mathrm{X}$ cross-section steel mold which is protected by valve pile shoe or precast pile tip. The installation procedure includes immersing the tube, pouring concrete, vibratory extubation, and curing the concrete. XCC pile is one of new displacement piles, and widely used in practice engineering. However, the theoretical research are far behind the application, especially the horizontal stress and displacement induced by pile installation. In this paper, an analytical solution is provided to study the horizontal stress and displacement distribution of surrounding soil. Then, based on the Fourth Yangtze River Bridge's north-line soft soil treatment engineering in Nanjing, the analytical solution was compared with the field test results. Finally, the geometric parameters of XCC pile (outsourcing diameter $a$, open arc 
distance $b$, and open arc angle $\theta$ ), the undrained strength $S_{u}$, and the pile hole pressure $P$ were discussed.

\section{Mathematical Model}

2.1. Definition of the Problem and Basic Assumption. Figure 1 shows that the elastoplastic soil, which is described by the Tresca model, is under initial stress $\sigma_{0}$ before the XCC pile installation. Then, the XCC pile installation progress is simplified as the expansion of a cavity from zero to the Xshaped cavity of the XCC pile cross-section. The soil around the pile enter into the passive limit balance state after the XCC pile installation. Thus, the X-shaped cavity internal pressure after XCC pile installation can be assumed as $P_{\text {lim }}=$ $\sigma_{0} \tan ^{2}\left(45^{\circ}+\varphi / 2\right)+2 c \tan \left(45^{\circ}+\varphi / 2\right)$, where $c$ and $\varphi$ are the soil cohesion and the internal friction angle, respectively. Additionally, the plain strain condition is assumed in the model. The Cartesian coordinates system is selected for the analysis. The origin of the coordinates is located at the center of the cavity. For the Cartesian coordinates system, the $x$ axis and $y$-axis are in the horizontal and vertical direction, respectively. The stress and strain are taken as positive in the positive direction of the coordinates system.

2.2. Basic Governing Equations. According to the elasticity [12], the stress around the X-shaped cavity should obey the fourth-order partial differential equation as follows:

$$
\nabla^{4} U=0
$$

where $\nabla$ is Laplace operator and $U$ is stress function in the plastic zone.

The three stress components in Cartesian coordinates system, $\sigma_{x}, \sigma_{y}$ and $\tau_{x y}$, around the X-shaped cavity can be determined by (1):

$$
\sigma_{x}=\frac{\partial^{2} U}{\partial y^{2}}, \quad \sigma_{y}=\frac{\partial^{2} U}{\partial x^{2}}, \quad \tau_{x y}=-\frac{\partial^{2} U}{\partial x \partial y} .
$$

According to the complex variable elasticity [13-17], the stress around the X-shaped cavity can be expressed with two stress functions $\varphi_{1}(z)$ and $\psi_{1}(z)$ as follows:

$$
\begin{gathered}
\sigma_{x}+\sigma_{y}=4 \operatorname{Re}\left[\varphi_{1}^{\prime}(z)\right], \\
\sigma_{y}-\sigma_{x}+2 i \tau_{x y}=2\left[\bar{z} \varphi_{1}^{\prime \prime}(z)+\psi_{1}^{\prime}(z)\right], \\
\frac{E}{1+\mu}(u+i v)=(3-4 \mu) \varphi_{1}(z)-z \varphi_{1}^{\prime}(\bar{z})-\psi_{1}(\bar{z}),
\end{gathered}
$$

where $\varphi_{1}^{\prime}(z)$ and $\varphi_{1}^{\prime \prime}(z)$ are the first and second derivative of the function $\varphi_{1}(z)$, respectively. $\psi_{1}^{\prime}(z)$ is the first derivative of the function $\psi_{1}(z) . \varphi_{1}^{\prime}(\bar{z})$ and $\psi_{1}(\bar{z})$ are the conjugate complex functions of the $\varphi_{1}^{\prime}(z)$ and $\psi_{1}(z) . u$ and $v$ are the displacement component acting in $x$-axis and $y$-axis directions, respectively. $E$ is the Young's modulus of the soil. $\mu$ is the Poisson ratio of the soil.

For obtaining the solution to calculate the stress and displacement distributions, a conformal mapping function is provided to map the outside of the X-shaped cavity in the $z$ plane onto the outside of the unit circle in the phase plane, namely, $\xi$-plane $\left(\xi=\zeta+i \eta=\rho e^{i \theta}\right)$ in Figure 2 . The conformal mapping function can be expressed in a series as follows:

$$
z=w(\xi)=c_{0} \xi+\sum_{k=1}^{n} c_{2 k-1} \xi^{1-2 k}, \quad|\xi| \leq 1
$$

where $n$ is integral number (in this paper, $n=7$ is selected for analysis and it can give enough accuracy). The constant coefficients $c_{0}$ and $c_{2 k-1}(k=1,2, \ldots, n)$ are real numbers and can be obtained by the iterative technique [18]. $z=x+i y(x$ and $y$ are the variables in the Cartesian coordinates system, $i=\sqrt{-1}$ ) is complex variable. $\xi$ is complex variable in the phase plane, $\xi=\rho e^{i \theta}$.

Substituting the conformal mapping function (4) into (3a), (3b), and (3c) leads to the following equations:

$$
\begin{gathered}
\sigma_{x}+\sigma_{y}=4 \operatorname{Re}\left[\frac{\varphi^{\prime}(\xi)}{w^{\prime}(\xi)}\right], \\
\sigma_{y}-\sigma_{x}+2 i \tau_{x y}=\frac{2}{w^{\prime}(\xi)}\left[\overline{w(\xi)}\left(\frac{\varphi^{\prime}(\xi)}{w^{\prime}(\xi)}\right)^{\prime}+\psi^{\prime}(\xi)\right], \\
\frac{E}{1+\mu}(u+i v)=\chi \varphi(\xi)-\frac{w(\xi)}{w^{\prime}(\xi)} \varphi^{\prime}(\bar{\xi})-\psi(\bar{\xi}),
\end{gathered}
$$

where $\varphi(\xi)=\varphi_{1}(w(\xi)), \psi(\xi)=\psi_{1}(w(\xi))$.

The two stress functions $\varphi_{1}(z)$ and $\psi_{1}(z)$ are transformed as $\varphi(\xi)$ and $\psi(\xi)$. To solve the stress functions $\varphi(\xi)$ and $\psi(\xi)$, the stress boundary conditions should be considered. From Figure 2, it can be seen that the stress boundary condition can be expressed as

$$
\left[\varphi(\xi)+\frac{w(\xi)}{w^{\prime}(\bar{\xi})} \varphi^{\prime}(\bar{\xi})+\psi^{\prime}(\xi)\right]_{s}=-p w(\xi),
$$

where $s$ is the $\mathrm{X}$-shaped cavity boundary curve and $P$ is the pressure at the $\mathrm{X}$-shaped cavity.

By the complex elasticity $[10,11]$, the stress functions $\varphi(\xi)$ and $\psi(\xi)$ can be written as follows:

$$
\begin{gathered}
\varphi(\xi)=\frac{1}{8 \pi(1-\mu)}\left(\bar{F}_{x}+i \bar{F}_{y}\right) \ln \xi+B w(\xi)+\varphi_{0}(\xi) \\
\psi(\xi)=-\frac{3-4 \mu}{8 \pi(1-\mu)}\left(\bar{F}_{x}-i \bar{F}_{y}\right) \ln \xi \\
+\left(B^{\prime}+i C^{\prime}\right) w(\xi)+\psi_{0}(\xi)
\end{gathered}
$$

where $\bar{F}_{x}$ and $\bar{F}_{y}$ are the composite surface force in $x$ and $y$ direction on the X-shaped cavity boundary, respectively. One has $B=\left(\sigma_{1}+\sigma_{2}\right) / 4\left(\sigma_{1}\right.$ and $\sigma_{2}$ are the principal stress at infinity) and $B^{\prime}+C^{\prime}=-(1 / 2)\left(\sigma_{1}-\sigma_{2}\right) e^{-2 i \alpha}(\alpha$ is the angle between the principal stress $\sigma_{1}$ and $o x$-axis). 


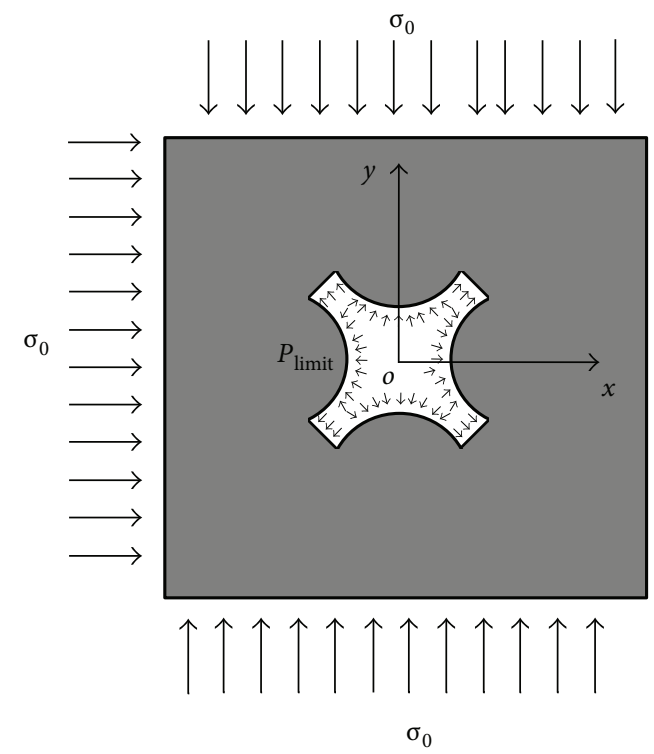

(a)

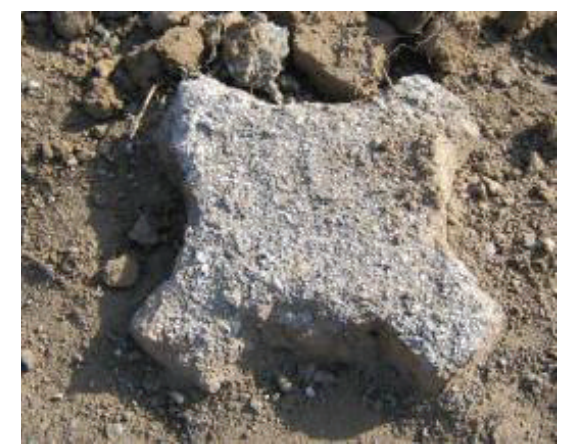

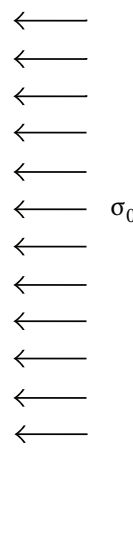


From the mechanics model in Figure 2, the following equations are established:

$$
\begin{gathered}
\bar{F}_{x}=\bar{F}_{y}=0, \\
B=\sigma_{0}, \\
B^{\prime}=C^{\prime}=0 .
\end{gathered}
$$

Additionally, the two stress functions $\varphi_{0}(\xi)$ and $\psi_{0}(\xi)$ can be expressed as the series:

$$
\begin{aligned}
& \varphi_{0}(\xi)=\sum_{k=0}^{n} \alpha_{2 k-1} \xi^{2 k-1}, \\
& \psi_{0}(\xi)=\sum_{k=1}^{n} \beta_{2 k-1} \xi^{2 k-1}
\end{aligned}
$$

where $\alpha_{2 k-1}$ and $\beta_{2 k-1}$ are the coefficients of the complex functions $\varphi_{0}(\xi)$ and $\psi_{0}(\xi)$. They can be determined by the boundary conditions.

Thus (7a) and (7b) can be simplified by substituting ( $8 \mathrm{a})$, (8b), (8c), (9a), and (9b) into (7a) and (7b) as

$$
\begin{gathered}
\varphi(\xi)=\sigma_{0} w(\xi)+\sum_{k=0}^{n} \alpha_{2 k-1} \xi^{2 k-1} \\
\psi(\xi)=\sum_{k=1}^{n} \beta_{2 k-1} \xi^{2 k-1} .
\end{gathered}
$$

Then, (10a) and (10b) are substituted into the stress boundary condition (6), and (6) can be transformed as follows:

$$
\varphi_{0}(\sigma)+\frac{w(\sigma)}{\overline{w^{\prime}(\sigma)}} \varphi_{0}^{\prime}(\bar{\sigma})+\psi_{0}(\bar{\sigma})=-\left(P+\sigma_{0}\right) z
$$

where, $\sigma=e^{i \theta}$.

Equations (10a) and (10b) are conjugated at both sides:

$$
\varphi_{0}(\bar{\sigma})+\frac{w(\bar{\sigma})}{w^{\prime}(\sigma)} \varphi_{0}^{\prime}(\sigma)+\psi_{0}(\sigma)=-\left(P+\sigma_{0}\right) \bar{z}
$$

Equations (10a), (10b), and (11) are multiplied by $(1 / 2 \pi i)$ $(d \sigma /(\sigma-\xi))$ and integrated along the cavity boundary $s$ at both sides:

$$
\begin{aligned}
& \frac{1}{2 \pi i} \int \varphi_{0}(\sigma) d \sigma+\frac{1}{2 \pi i} \int \frac{w(\sigma)}{w^{\prime}(\bar{\sigma})} \varphi_{0}^{\prime}(\bar{\sigma}) d \sigma \\
& \quad+\frac{1}{2 \pi i} \int \psi_{0}(\bar{\sigma}) d \sigma=\frac{1}{2 \pi i} \int-\left(P+\sigma_{0}\right) w(\sigma) d \sigma \\
& \frac{1}{2 \pi i} \int \varphi_{0}(\bar{\sigma}) d \sigma+\frac{1}{2 \pi i} \int \frac{w(\bar{\sigma})}{w^{\prime}(\sigma)} \varphi_{0}^{\prime}(\sigma) d \sigma \\
& +\frac{1}{2 \pi i} \int \psi_{0}(\sigma) d \sigma=\frac{1}{2 \pi i} \int-\left(P+\sigma_{0}\right) w(\bar{\sigma}) d \sigma
\end{aligned}
$$

According to the principle of the series expansion, the terms of $w(\sigma) / w^{\prime}(\bar{\sigma})$ can be expressed as follows:

$$
\begin{aligned}
\frac{w(\sigma)}{w^{\prime}(\bar{\sigma})}= & b_{2 k-3} \sigma^{2 k-3}+b_{2 k-5} \sigma^{2 k-5}+\cdots+b_{1} \sigma^{1} \\
& +b_{-1} \sigma^{-1}+O\left(\frac{1}{\sigma^{3}}\right)
\end{aligned}
$$

Equation (4) is substituted into (14) and can be written in matrix form as follows:

$$
A B=C,
$$

where

$$
\begin{gathered}
A=\left[\begin{array}{ccccccc}
-\bar{c}_{0} & \bar{c}_{1} & 3 \bar{c}_{3} & 5 \bar{c}_{5} & \cdots & \cdots & (2 n-3) \bar{c}_{2 n-3} \\
& -\bar{c}_{0} & \bar{c}_{1} & 3 \bar{c}_{3} & \cdots & \cdots & (2 n-5) \bar{c}_{2 n-5} \\
& & -\bar{c}_{0} & \bar{c}_{1} & \cdots & \cdots & (2 n-7) \bar{c}_{2 n-7} \\
& & & \ddots & \cdots & \cdots & \vdots \\
& & & \ddots & \cdots & \vdots \\
& & & & -\bar{c}_{0} & \bar{c}_{1} \\
& \\
& & & & & & -\bar{c}_{0} \\
b_{-1} & b_{1} & b_{3} & b_{5} & \cdots & b_{2 n-3}
\end{array}\right]^{T}, \\
C=\left[\begin{array}{lllllll}
c_{1} & c_{3} & c_{5} & c_{7} & \cdots & c_{2 n-1}
\end{array}\right]^{T} .
\end{gathered}
$$

After the coefficients $b_{-1}$ and $b_{2 k-3}(k=1,2,3 \ldots, n)$ are determined by solving (15), substituting the expression of $w(\sigma) / w^{\prime}(\bar{\sigma})$ into (13a), the equation for calculating the coefficients of the stress functions can be obtained as follows:

$$
\left[\begin{array}{ll}
E_{n} & M \\
M & E_{n}
\end{array}\right] \alpha=N,
$$

where

$$
\begin{gathered}
M=\left[\begin{array}{ccccc}
b_{1} & 3 b_{3} & \cdots & (2 n-3) b_{2 n-3} & 0 \\
b_{3} & 3 b_{5} & \cdots & 0 & 0 \\
\vdots & \cdots & \cdots & 0 & 0 \\
b_{2 n-3} & 0 & \cdots & 0 & 0 \\
0 & 0 & \cdots & 0 & 0
\end{array}\right], \\
\alpha=\left[\begin{array}{llllllll}
\alpha_{1} & \alpha_{3} & \cdots & \alpha_{2 n-1} & \bar{\alpha}_{1} & \bar{\alpha}_{3} & \cdots & \bar{\alpha}_{2 n-1}
\end{array}\right]^{T}, \\
N=-\left(P+\sigma_{0}\right)\left[\begin{array}{llllllll}
c_{1} & c_{3} & \cdots & c_{2 n-1} & \bar{c}_{1} & \bar{c}_{3} & \cdots & \bar{c}_{2 n-1}
\end{array}\right]^{T},
\end{gathered}
$$

$\bar{M}$ is the conjugate matrix of $M$, and $E_{n}$ is $n$-dimension unit matrix.

Similarly, the coefficient $\beta_{2 k-1}$ of the stress function $\psi_{0}(\xi)$ can be calculated like $\alpha_{2 k-1}$. Thus, the stress functions $\varphi_{0}(\xi)$ and $\psi_{0}(\xi)$ are completely determined, and the horizontal stress change and displacement are obtained by solving (5a), (5b), and (5c).

2.3. Elastoplastic Boundary (EP Boundary). Normally, the surrounding soil will enter into plastic stage after XCC pile installation and lead to a formation of a plastic zone around 
the X-shaped cavity wall. Therefore an elastoplastic analysis is necessary. The nonaxisymmetric problem in the original plane can be transformed into axisymmetric problem in the phase plane by the conformal mapping technique. Thus, it can be easily processed in the phase plane for the axisymmetric characteristics. Considering an element at a radial distance $\rho$ from the center of the cavity, the equation of equilibrium in the phase plane can be expressed as follows:

$$
\frac{\partial \Delta \sigma_{\rho}}{\partial \rho}+\frac{\Delta \sigma_{\rho}-\Delta \sigma_{\theta}}{\rho}=0
$$

where $\Delta \sigma_{\rho}$ and $\Delta \sigma_{\theta}$ are radial and circumference stress increment, respectively and $\rho$ is the radial position of the soil particle.

Note that the Tresca yield criteria has the following form

$$
\Delta \sigma_{\rho}-\Delta \sigma_{\theta}=2 S_{u}
$$

where $S_{u}$ is the undrained strength of the soil.

The stress boundary conditions in the phase plane are

$$
\begin{gathered}
\Delta \sigma_{\rho}=P \quad \text { at } \rho=1, \\
\Delta \sigma_{\rho}=0 \quad \text { at } \rho \longrightarrow \infty .
\end{gathered}
$$

Combining (19), (20), and the stress boundary conditions, the stress in the plastic zone can be obtained:

$$
\begin{gathered}
\Delta \sigma_{\rho}^{p}=-2 S_{u} \ln \rho-P, \\
\Delta{\sigma_{\theta}}^{p}=-2 S_{u}(\ln \rho+1)-P .
\end{gathered}
$$

In the elastic zone, the stress can be written as

$$
\begin{aligned}
& \Delta \sigma_{\rho}^{e}=\lambda \frac{P}{\rho^{2}}, \\
& \Delta \sigma_{\theta}^{e}=\lambda \frac{P}{\rho^{2}},
\end{aligned}
$$

where $\lambda$ is the stress redistribution coefficient in the elastic zone.

At the EP boundary, the stress in the elastic zone should also obey the Tresca yield criteria. Thus, the stress redistribution coefficient in the elastic zone can be expressed as follows by substituting (23a) and (23b) into (22a) and (22b):

$$
\begin{gathered}
\sigma_{\rho}=S_{u} \frac{\rho_{b}^{2}}{\rho^{2}}, \\
\sigma_{\theta}=-S_{u} \frac{\rho_{b}^{2}}{\rho^{2}},
\end{gathered}
$$

where $\rho_{b}$ is the radius of the plastic zone in the phase plane.

At the EP boundary, the stress in the plastic zone should be equal to that in the elastic zone. Therefore, combining (22a), (22b) and (24a), (24b) the relationship of the pressureplastic zone radius can be expressed as follows:

$$
\rho_{b}=e^{1+P / S_{u} / 2} \text {. }
$$

Substituting the limit cavity pressure $P_{\text {lim }}$ into (25), the radius of the plastic zone in $\xi$-plane after the XCC pile installation can be obtained as follows:

$$
\rho_{b}=e^{1+P_{\lim } / S_{u} / 2}
$$

The radius of the plastic zone in the physical plane can be obtained by combining (4) and (25):

$$
R_{b}(\theta)=\left|w\left(\rho_{b} e^{i \theta}\right)\right|,
$$

where the plastic zone $R_{b}(\theta)$ is the function of the polar angle.

According to the above analysis, EP boundary is circle curve with radius equal to $\rho_{b}$ in the phase plane. The real EP boundary in the physical plane is not circular curve and it can be calculated by (27). However, the EP boundary in the physical plane is closed to circular curve far away from the $\mathrm{X}$-shaped cavity from (27). Therefore, the radius of the plastic zone can be assumed as follows:

$$
R_{b}=\max \left(\left|w\left(\rho_{b} e^{i \theta}\right)\right|\right),
$$

where $R_{b}$ is the maximum radius of the plastic zone in the physical plane.

2.4. The Horizontal Stress and Displacement Solutions in the Elastic Zone. After the soil around the cavity wall enters yield state, the stress in the elastic zone has a redistribution effect and the stress in the elastic zone cannot be calculated by the elastic analysis directly. However, the stress redistribution effect can be considered by introducing a coefficient $\lambda$ into the elastic analysis. In other words, the new stress functions $\lambda \varphi(\xi)$ and $\lambda \psi(\xi)$ instead of $\varphi(\xi)$ and $\psi(\xi)$ are introduced into the governing equations. Thus the governing equations (5a), (5b), and (5c) of the elastic zone can be expressed as

$$
\begin{gathered}
\sigma_{x}+\sigma_{y}=4 \operatorname{Re}\left[\lambda \frac{\varphi^{\prime}(\xi)}{w^{\prime}(\xi)}\right] \\
\sigma_{y}-\sigma_{x}+2 i \tau_{x y}=\frac{2}{w^{\prime}(\xi)}\left[\lambda w(\bar{\xi})\left(\frac{\varphi^{\prime}(\xi)}{w^{\prime}(\xi)}\right)^{\prime}+\lambda \psi^{\prime}(\xi)\right]
\end{gathered}
$$

$$
2 G\left(u_{x}+i u_{y}\right)=(3-4 \mu) \lambda \varphi(\xi)-\lambda \frac{w(\xi)}{w^{\prime}(\bar{\xi})} \varphi^{\prime}(\bar{\xi})-\lambda \psi(\bar{\xi}) .
$$

Under the undrained condition, the volume change of the X-shaped cavity induced by the XCC pile installation is equivalent to the change in position of the EP boundary. The mathematical relation can be expressed as follows:

$$
A_{x}=\pi R_{b}^{2}-\pi\left(R_{b}-u_{b}\right)^{2}
$$

where $A_{x}$ is the area of $\mathrm{X}$-shaped cavity, $R_{b}$ is the radius of the plastic zone, and $u_{p}$ is the radial displacement at the EP boundary. 
TABLE 1: Physical-mechanical properties of soils on site.

\begin{tabular}{lcccccccc}
\hline Soil name & $h(\mathrm{~m})$ & $w(\%)$ & $\gamma\left(\mathrm{kN} / \mathrm{m}^{3}\right)$ & $v$ & $E_{s}(\mathrm{MPa})$ & $e$ & $c(\mathrm{kPa})$ & $\varphi\left(^{\circ}\right)$ \\
\hline Silt clay & 2.00 & 30.5 & 18.50 & 0.3 & 5.49 & 0.913 & 26.4 & 15.1 \\
Silt clay & 4.60 & 41.4 & 17.90 & 0.3 & 2.97 & 1.159 & 10.8 & 3.4 \\
Silt soil & 3.40 & 30.3 & 18.60 & 0.3 & 11.68 & 0.897 & 12.7 \\
Silt clay & 3.70 & 41.4 & 17.90 & 0.3 & 2.97 & 1.159 & 10.8 & 26.4 \\
Silt soil & 2.00 & 30.3 & 18.60 & 0.3 & 11.68 & 0.897 & 12.7 \\
Silt clay & 1.60 & 32.9 & 18.80 & 0.3 & 4.41 & 0.915 & 26.4 \\
Silt soil & 0.30 & 30.3 & 18.60 & 0.3 & 11.68 & 0.897 & 16.1 \\
\hline
\end{tabular}

Notes: $h$ : the thickness of the soil layer; $w$ : the moisture content; $\gamma$ : the bulk density; $v$ : the Poisson ratio; $E_{s}$ : the compression modulus; $e$ : the void ratio; $c$ : the cohesion; $\varphi$ : the internal friction angle.

The $u_{b}^{2}$ is higher order driblet and can be ignored and thus (28) can be expressed as

$$
u_{b}=\frac{A_{x}}{2 \pi R_{b}} .
$$

The stress redistribution factor $\lambda$ can be obtained by solving the coupled equations (28), (29c), and (31); then the new stress functions $\lambda \varphi(\xi)$ and $\lambda \psi(\xi)$ can be obtained. Substituting the new stress functions into the governing equation of the elastic zone (29a), (29b), and (29c), the horizontal stress and displacement in the elastic zone can be determined.

\section{Verification}

3.1. Engineering Description. The Fourth Yangtze River Bridge's north-line soft soil treatment field is located in Nanjing, China. The total length of the soft ground improvement engineering is $29.0 \mathrm{~km}$. Physical-mechanical properties of soils on site are shown in Table 1 . The form of plumshaped layout is carried out in the engineering. The pile spacing and length are $2.2 \mathrm{~m}$ and $12 \mathrm{~m}$, respectively. The three parameters of the XCC pile cross-section the outsourcing diameter (parameter $a$ ), the open arc distance (parameter $b$ ), and the open arc angle (parameter $\theta$ ) are $611 \mathrm{~mm}, 120 \mathrm{~mm}$, and $130^{\circ}$, respectively (see Figure 3 ).

The arrangement of the test equipment and measuring points are shown in Figure 4. The location of the test instrument is concluded as follows. (1) Inclinometer tubes were buried at the distance from the XCC pile center: $1 \mathrm{~m}, 2 \mathrm{~m}$, and $3.5 \mathrm{~m}$, respectively. (2) Pore water pressure gauges were buried at the depth of $6 \mathrm{~m}$ and $9 \mathrm{~m}$, and the distances from the pile center equal $1 \mathrm{~m}, 2 \mathrm{~m}$, and $3.5 \mathrm{~m}$, respectively. (3) Earth pressure cells were buried at the depth of $3 \mathrm{~m}$ and $6 \mathrm{~m}$, and the distances from the pile center equal $1 \mathrm{~m}, 2 \mathrm{~m}$, and $3.5 \mathrm{~m}$, respectively.

3.2. Comparison on the Theoretical Calculated Results with Field Test Results. The radial stress and displacement at the depth of 3 meters are selected for comparison, which are shown in Figure 5. The radial stress and displacement are plotted against the normalized radius, $r / R$, where the variable $r$ is the radial position and $R$ is the radius of the outsourcing round of XCC pile cross-section. The stress and

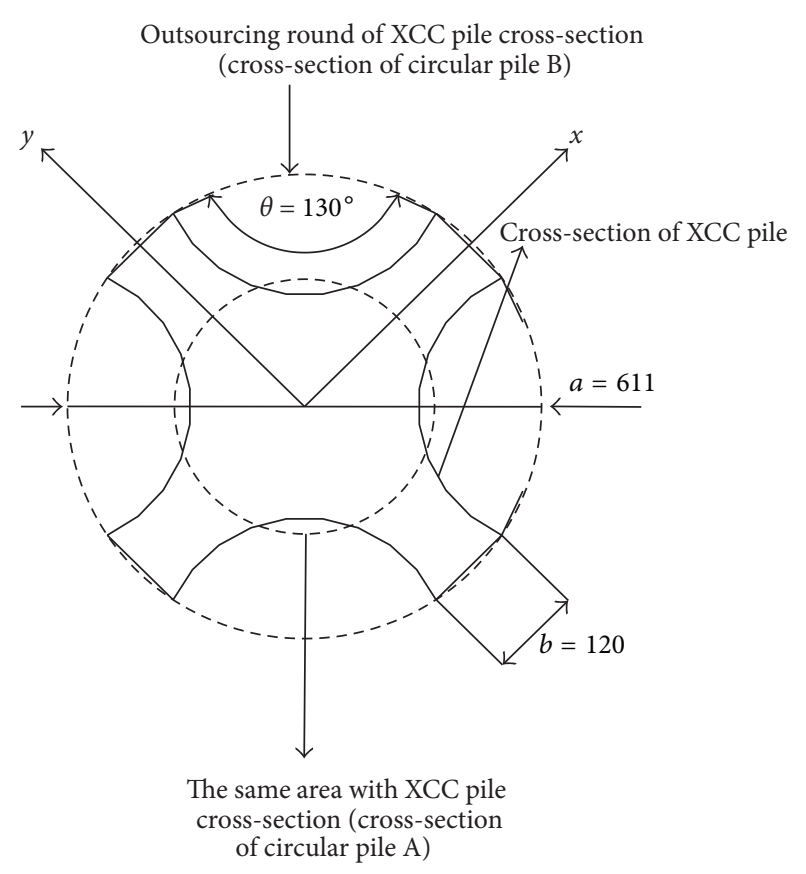

FIGURE 3: Geometry of XCC pile cross-section.

displacement of soil around the XCC pile calculated by this study are similar to those of the measured results on site. Therefore, this study can simulate the stress and displacement induced by XCC pile installation well. Additionally, the stress and radial displacement decrease rapidly with the distance from the pile center. The radius of the influence zone induced by the XCC pile installation is about $12 R$.

Figure 5 also gives the comparison between the XCC pile, the circular pile A (the same area with XCC pile crosssection), and the circular pile B (outsourcing round of XCC pile cross-section). The results show that the displacements for circular pile B, which is calculated by cylindrical cavity expansion method (CEM), are larger than those of the circular pile A and XCC pile. Additionally, the displacement of circular pile A and that of XCC pile are almost the same. In other words, the area of the pile cross-section governs the displacement induced by the pile installation. Therefore, it is reasonable to calculate displacement caused by XCC pile installation with circular pile A instead of XCC pile. As shown 


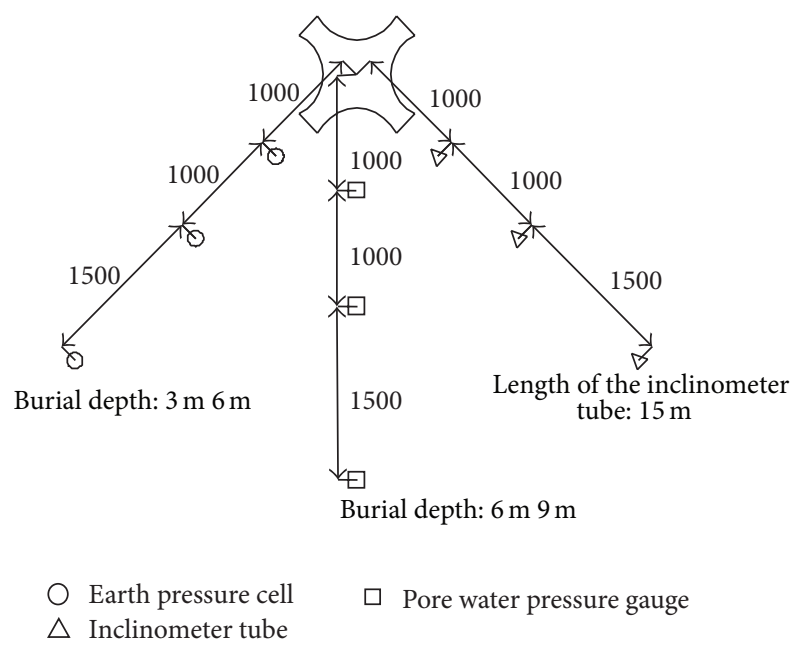

FIgURE 4: Equipment arrangement and measuring points on site.

in Figure 5(b), the stress of circular pile B is also larger than those of the circular pile A and XCC pile. However, the stress of circular pile A and XCC pile is different which means the stress is related to the pile cross-section. Thus, it is not accurate to calculate the stress or excess pore pressure with circular pile A instead of XCC pile. When it refers to the stress or excess pore pressure, this study should be used.

\section{Parametric Studies}

In order to provide engineers and researchers with calculation charts and tables for estimating horizontal stress, displacements, and the radius of the plastic zone induced by XCC pile installation, a parametric study is carried out. The stress, displacement, and the radius of the plastic zone have many influence factors. This paper focus on the factors of outsourcing diameter, open arc distance, open arc angle, the pile hole pressure $P$, and the undrained strength $S_{u}$. The stress, displacement along $x$-axis in the elastic zone, and the radius of the plastic zone are analyzed. The Young's modulus of the soil is selected for $5 \mathrm{MPa}$ and the Poisson's ratio is 0.3 . The influence characteristics of the parameters on the stress, displacement of the soil around the pile, and the radius of the plastic zone are obtained by the parametric study.

4.1. The Radius of the Plastic Zone Analysis. From (26) and (28), the radius of the plastic zone is the function of the ratio of the limit pressure $P_{\text {lim }}$, the undrained strength $P_{\text {lim }} / S_{u}$, and the parameters of the XCC pile cross-section (the outsourcing diameter, the open arc angle, and the open distance). Thus, the four parameters are selected for the parametric studies.

The plastic zone radius $R_{p}$ is plotted against the variable of $P_{\text {lim }} / S_{u}$ with different parameters of the XCC pile crosssection in Figure 6. As shown in Figures 6(a), 6(b), and 6(c), the higher $P_{\text {lim }} / S_{u}$ develops the larger plastic zone radius $R_{p}$. From Figure 6(a), it can be seen that the outsourcing diameter $a$ increases with the increasing plastic zone radius $R_{p}$, provided that all other factors are held

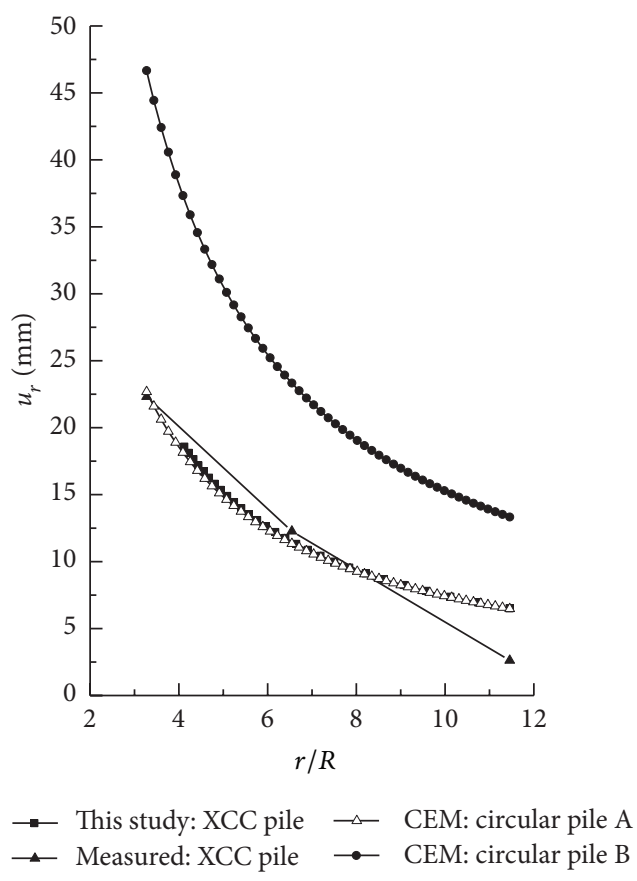

(a)

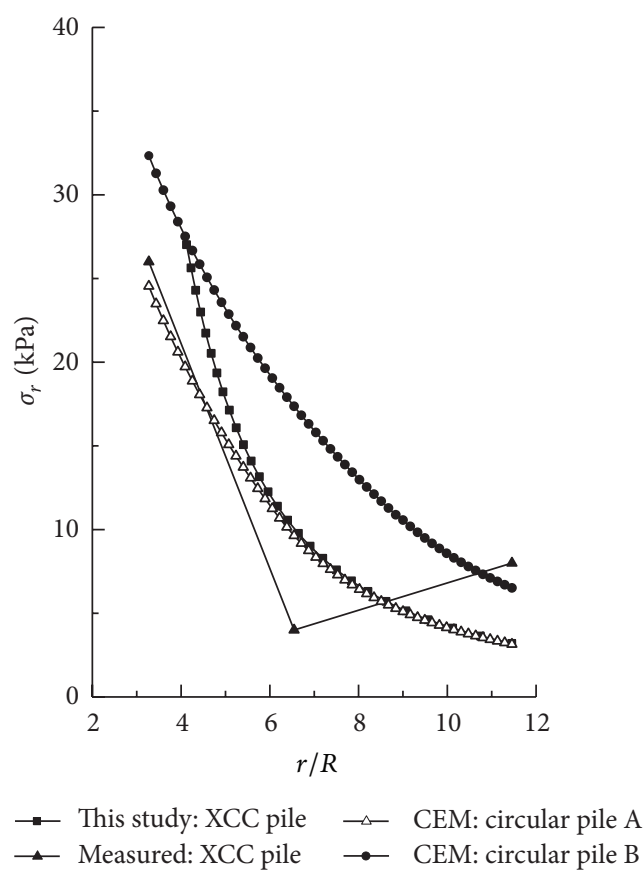

(b)

FIgURE 5: Comparison between this study and measured data: (a) radial displacement, (b) radial stress.

constants. With the variable of $a$ range from $500 \mathrm{~mm}$ to $1000 \mathrm{~mm}$, it is found that the increasing amplitude of the $R_{p}$ increases with the increasing $P_{\lim } / S_{u}$, provided that the variables of $b$ and $\theta$ are constant. Figure 6(b) shows that the open arc distance $b$ has similar characteristics as the outsourcing diameter $a$. Figure 6(c) shows that the open arc angle $\theta$ reduces with the increasing plastic zone radius 


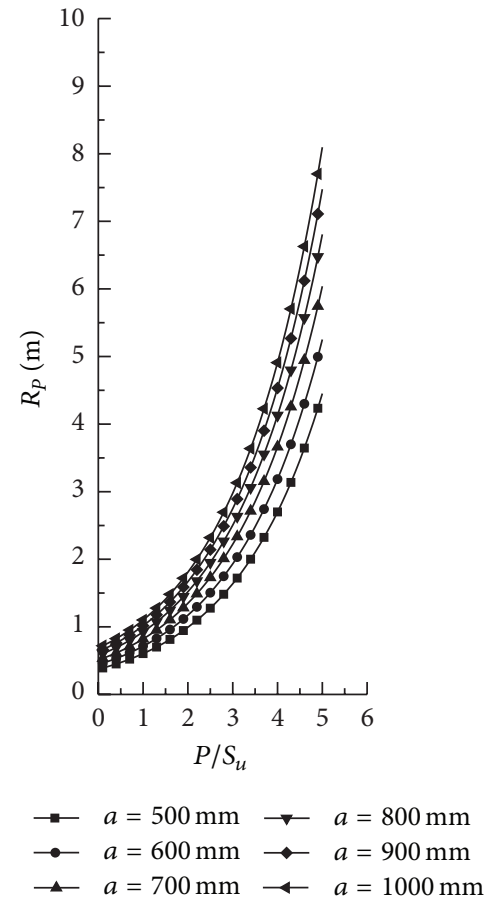

(a)
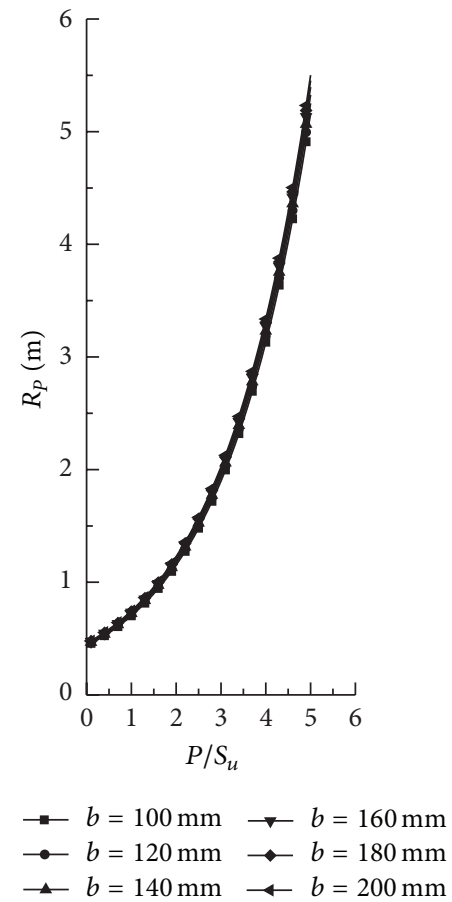

(b)

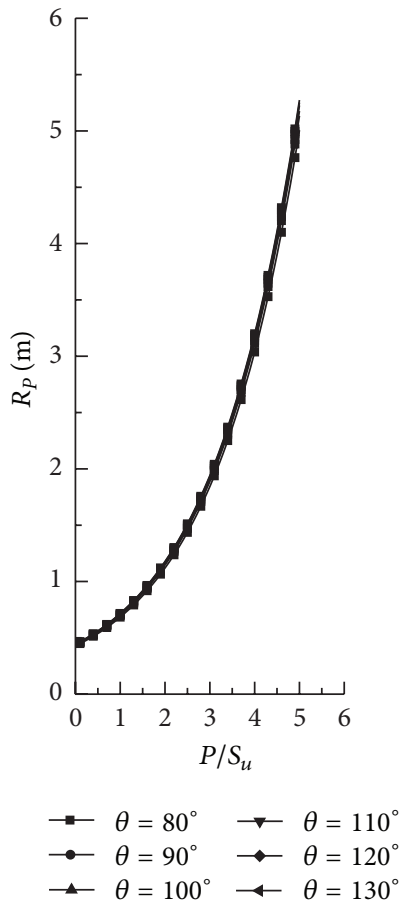

(c)

Figure 6: Variation of the plastic radius $R_{p}$ with different geometric parameters $(a, b, \theta)$ and $P_{\lim } / S_{u}$ : (a) $a=500 \mathrm{~mm}$ to $1000 \mathrm{~mm}, b=120 \mathrm{~mm}$, $\theta=90^{\circ}$; (b) $a=600 \mathrm{~mm}, b=120 \mathrm{~mm}$ to $200 \mathrm{~mm}, \theta=90^{\circ}$; (c) $a=600 \mathrm{~mm}, b=120 \mathrm{~mm}, \theta=80^{\circ}$ to $130^{\circ}$.

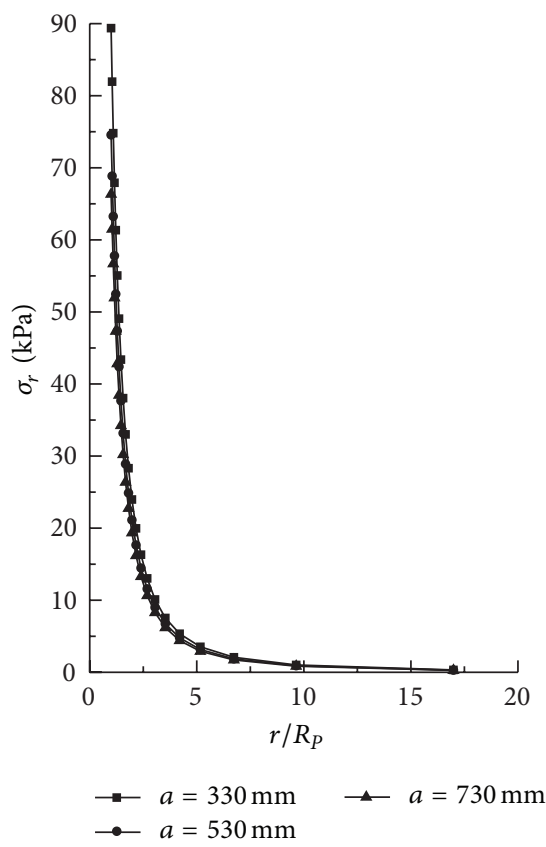

(a)

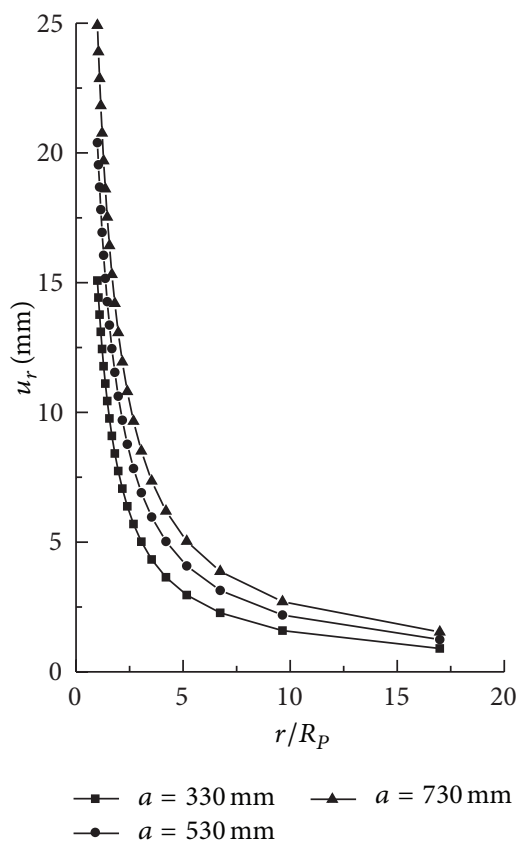

(b)

FIGURE 7: Radial stress and displacement distribution of different outsourcing diameter $a$ along the radial direction $\left(b=110 \mathrm{~mm}, \theta=90^{\circ}, S_{u}=\right.$ $10 \mathrm{kPa}$ ): (a) radial stress, (b) radial displacement. 


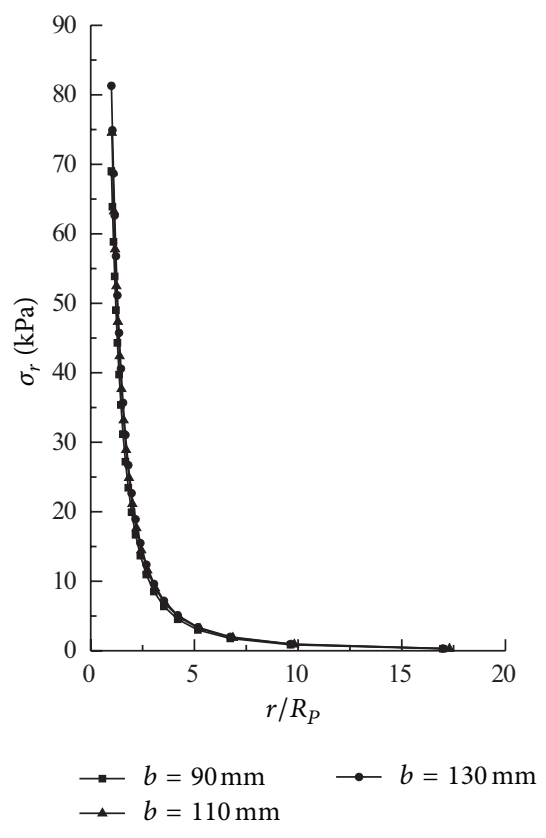

(a)

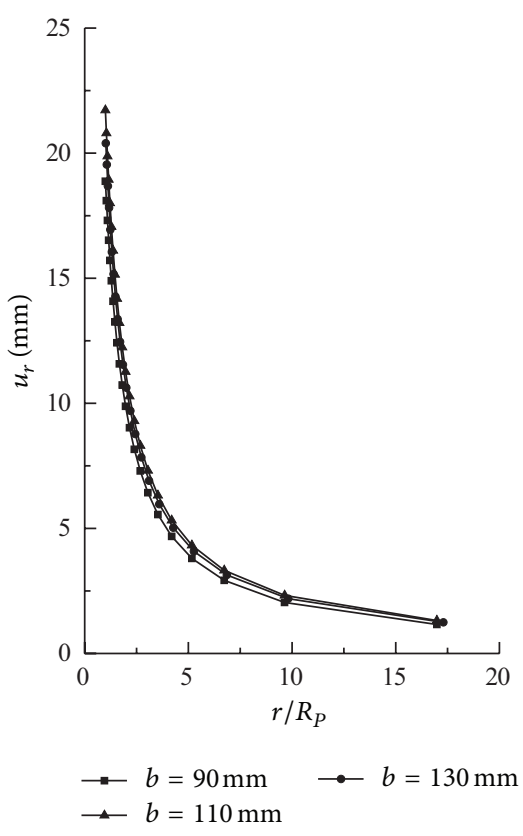

(b)

Figure 8: Radial stress and displacement distribution of different open arc angle $b$ along the radial direction $\left(a=530 \mathrm{~mm}, \theta=90^{\circ}, S_{u}=\right.$ $10 \mathrm{kPa}$ ): (a) radial stress, (b) radial displacement.

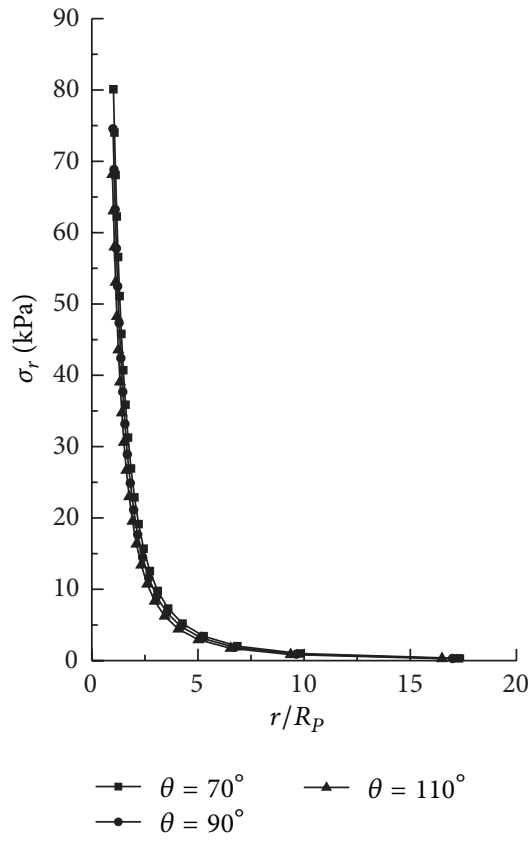

(a)

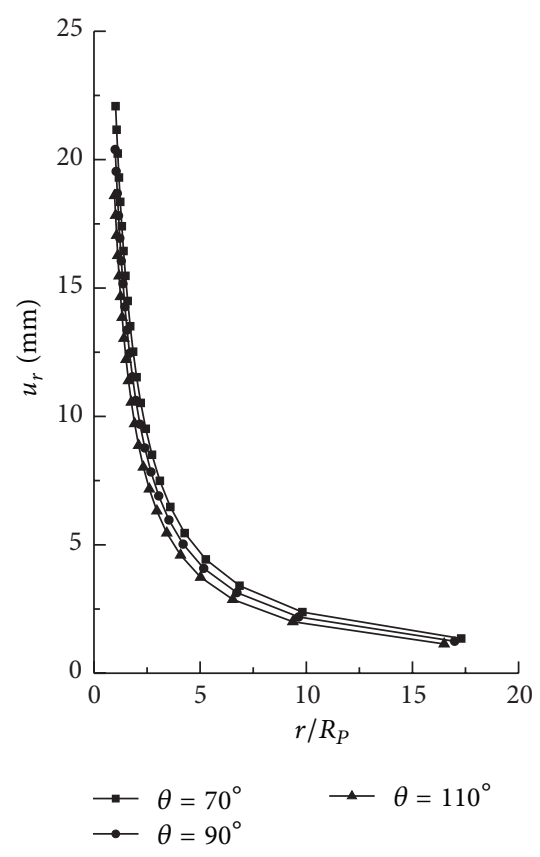

(b)

FIGURE 9: Radial stress and displacement distribution of different open arc angle $\theta$ along the radial direction $\left(a=530 \mathrm{~mm}, b=110 \mathrm{~mm}, S_{u}=\right.$ $10 \mathrm{kPa}$ ): (a) radial stress, (b) radial displacement.

$R_{p}$. However, the plastic zone radius $R_{p}$ is not sensitive to the open arc distance $b$ and open arc angle $\theta$. In all, the outsourcing diameter $a$ is the most obvious influence parameter of the radius of the plastic zone among the three geometric parameters of XCC pile cross-section.
4.2. Stress and Displacement Distribution Analysis. Based on the three geometric parameters of the XCC pile cross-section and the undrained strength $S_{u}$, the influence characteristics of the stress changes and displacement in the elastic zone are obtained. The limit pressure $P_{\text {lim }}$ is assumed to be $10 \mathrm{kPa}$. 


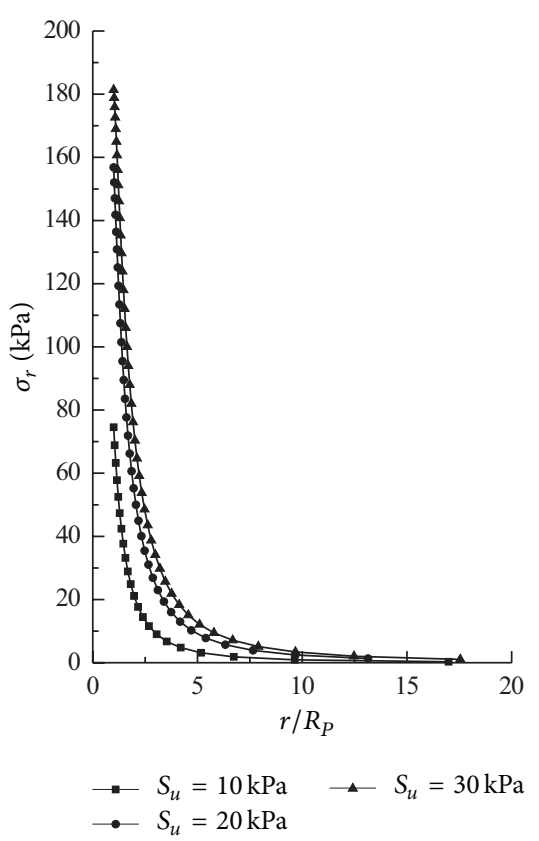

(a)

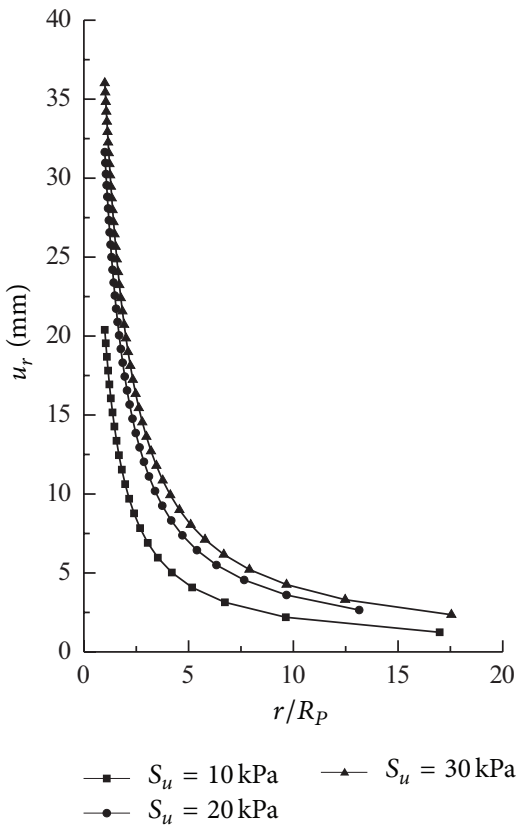

(b)

Figure 10: Radial stress and displacement distribution of different $S_{u}$ along the radial direction $\left(a=530 \mathrm{~mm}, b=110 \mathrm{~mm}, \theta=90^{\circ}\right)$ : (a) radial stress, (b) radial displacement.

As shown in Figure 7, with the outsourcing diameter range from $330 \mathrm{~mm}$ to $730 \mathrm{~mm}$, the radial displacement increases with the increasing outsourcing diameter $a$ in the elastic zone, provided that all other factors are held constant. However, the stresses do not almost change. It can be concluded that the outsourcing diameter has little influence on the horizontal stress in the elastic zone. It can be seen that the radius of stress influence zone is about $17 R_{p}$, which is less than that of the stress influence zone (more than $17 R_{p}$ ) by comparing Figure 7(a) with Figure 7(b). From Figures 8 and 9 , it can be observed that both of the open arc distance and open arc angle have little influence on the horizontal stress and displacement.

Figure 10(a) shows that the stress increased with the increasing of undrained strength $S_{u}$ in the elastic zone. From Figure 10(b), it can be seen that the larger the undrained strength $S_{u}$ is, the larger the displacement will be. It is because the radius of the plastic zone $R_{p}$ reduces with the increasing $S_{u}$. However, the volume of the plastic zone is constant under Tresca condition, and the volume change induced by the XCC pile installation can only be manifested in the elastic zone. Thus, the volume change in the elastic zone increases with the reducing $R_{p}$ and the displacement in the elastic zone will increase.

\section{Conclusions}

An analytical solution considering the pile cross-section shape for the horizontal stress and displacement of the soil around the XCC pile after installation is presented in this study. An elastoplastic model for calculating the horizontal stress and displacement is established by complex variables. Some main results can be concluded as follows.

(1) Compared with the data of the field test, it can be seen that the elastoplastic model calculation results on the horizontal stress and displacement of the soil around the XCC pile after installation are in agreement with those of field results. A theoretical method for studying the special shaped piles installation is provided in this paper.

(2) The radius of the plastic zone caused by the XCC pile installation can be calculated conveniently by this study. The $R_{p}$ increased with the increasing of $P_{\lim } / S_{u}$, outsourcing diameter $a$, and open arc distance $b$ while it decreases with the increasing of open arc distance $\theta$. The outsourcing diameter $a$ is the most obvious influence parameter of the radius of the plastic zone among the three geometric parameters $(a, b$, and $\theta)$ of XCC pile cross-section.

(3) The radial displacement increases with the increasing of outsourcing diameter $a$ in the elastic zone, and the outsourcing diameter $a$ has little influence on the horizontal stress in the elastic zone. The stress and displacement increased with the increasing of undrained strength $S_{u}$ obviously in the elastic zone. Both of the open arc distance $b$ and the open arc angle $\theta$ have little influence on the horizontal stress and displacement. The extent of the displacement influence zone is larger than that of the stress influence zone. 


\section{Acknowledgments}

The authors wish to thank the National Science Foundation of China (nos. 51278170 and U1134207), Program for Changjiang Scholars and Innovative Research Team in Hohai University (no. IRT1125), and 111 Project (no. B13024) for financial support.

\section{References}

[1] X. Xu, H. Liu, and B. M. Lehane, "Pipe pile installation effects in soft clay," Proceedings of the Institution of Civil Engineers: Geotechnical Engineering, vol. 159, no. 4, pp. 285-296, 2006.

[2] A. S. Vesic, "Expansion of cavities in infinite soil mass," Journal of the Soil Mechanics \& Foundations Division, vol. 98, no. 3, pp. 265-290, 1972.

[3] H. S. Yu, Cavity Expansion Methods in Geomechanics, Kluwer Academic Publishers, London, UK, 2000.

[4] L. F. Cao, C. I. Teh, and M.-F. Chang, "Analysis of undrained cavity expansion in elasto-plastic soils with non-linear elasticity," International Journal for Numerical and Analytical Methods in Geomechanics, vol. 26, no. 1, pp. 25-52, 2002.

[5] R. Salgado and M. F. Randolph, "Analysis of cavity expansion in sand," International Journal For Numerical and Analytical Methods in Geomechanics, vol. 26, no. 1, pp. 175-192, 2001.

[6] Y. N. Abousleiman and S. L. Chen, "Exact undrained elastoplastic solution for cylindrical cavity expansion in modified Cam Clay soil," Géotechnique, vol. 62, no. 5, pp. 447-456, 2012.

[7] I. F. Collins and H. S. Yu, "Undrained cavity expansions in critical state soils," International Journal for Numerical and Analytical Methods in Geomechanics, vol. 20, no. 7, pp. 489-516, 1996.

[8] M. M. Baligh, "Strain path method," Journal of Geotechnical Engineering, vol. 111, no. 9, pp. 1108-1136, 1985.

[9] C. Sagaseta, A. J. Whittle, and M. Santagata, "Deformation analysis of shallow penetration in clay," International Journal for Numerical and Analytical Methods in Geomechanics, vol. 21, no. 10, pp. 687-719, 1997.

[10] D. R. Gill and B. M. Lehane, "Extending the strain path method analogy for modelling penetrometer installation," International Journal For Numerical and Analytical Methods in Geomechanics, vol. 24, no. 5, pp. 175-192, 2000.

[11] Y. R. Lv, H. L. Liu, X. M. Ding, and G. Q. Kong, "Field tests on bearing characteristics of X-section pile composite foundation," Journal of Performance of Constructed Facilities, vol. 26, no. 2, pp. 180-189, 2012.

[12] S. P. Timoshenko and J. N. Goodier, Theory of Elasticity, McGraw-Hill, New York, NY, USA, 1970.

[13] N. I. Muskhelishvili, Some Basic Problems of the Mathematical Theory of Elasticity, P. Noordhoff, Groningen, The Netherlands, 1963.

[14] J. W. Brown, Complex Variables and Applications, McGraw-Hill, New York, NY, USA, 2008.

[15] A. Verruijt, "Deformations of an elastic half plane with a circular cavity," International Journal of Solids and Structures, vol. 35, no. 21, pp. 2795-2804, 1998.

[16] G. H. Lei, C. W. W. Ng, and D. B. Rigby, "Stress and displacement around an elastic artificial rectangular hole," Journal of Engineering Mechanics, vol. 127, no. 9, pp. 880-890, 2001.

[17] O. E. Strack and A. Verruijt, "A complex variable solution for a deforming buoyant tunnel in a heavy elastic half-plane,"
International Journal for Numerical and Analytical Methods in Geomechanics, vol. 26, no. 12, pp. 1235-1252, 2002.

[18] G. E. Exadaktylos, P. A. Liolios, and M. C. Stavropoulou, "A semi-analytical elastic stress-displacement solution for notched circular openings in rocks," International Journal of Solids and Structures, vol. 40, no. 5, pp. 1165-1187, 2003. 


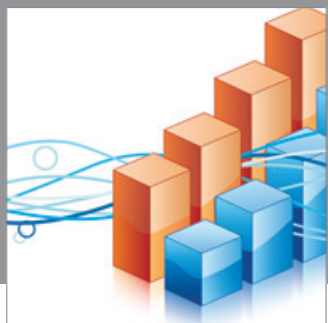

Advances in

Operations Research

mansans

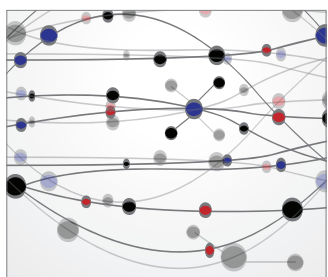

The Scientific World Journal
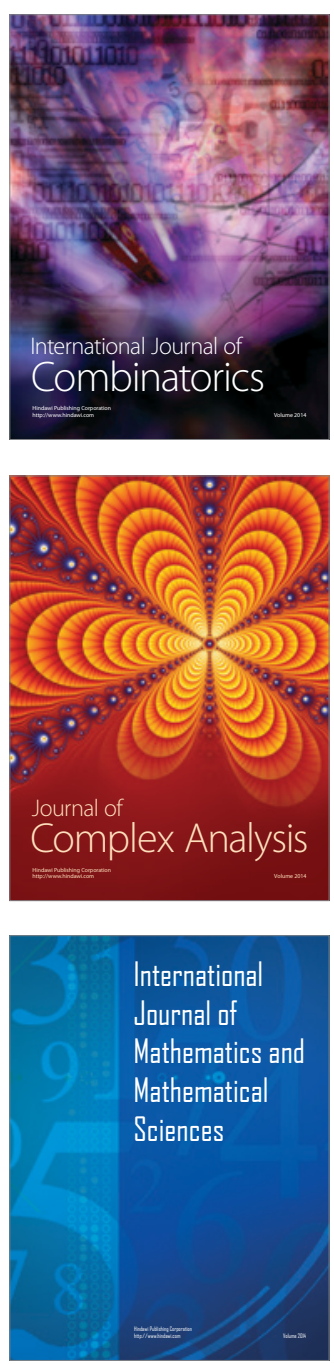
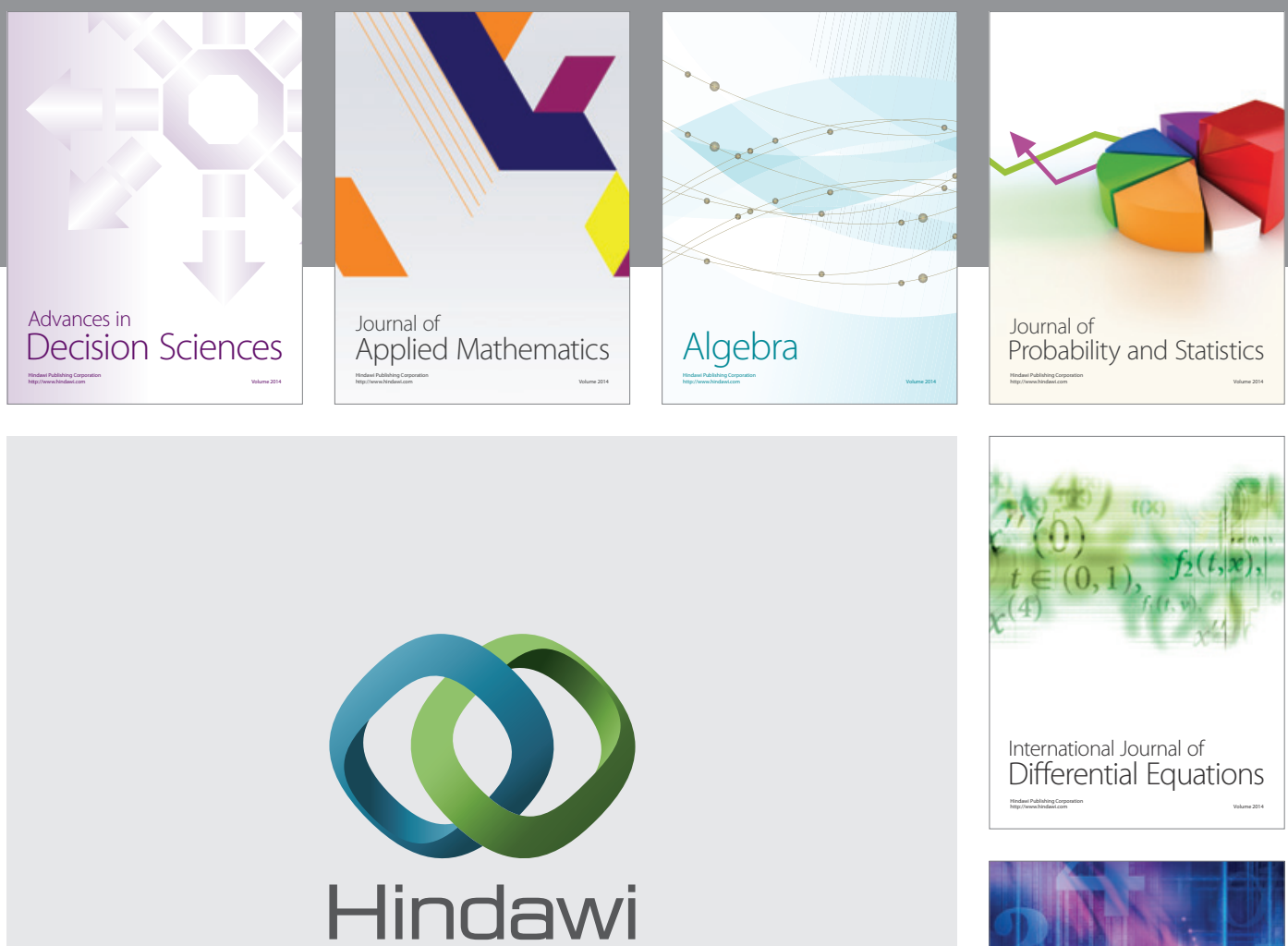

Submit your manuscripts at http://www.hindawi.com
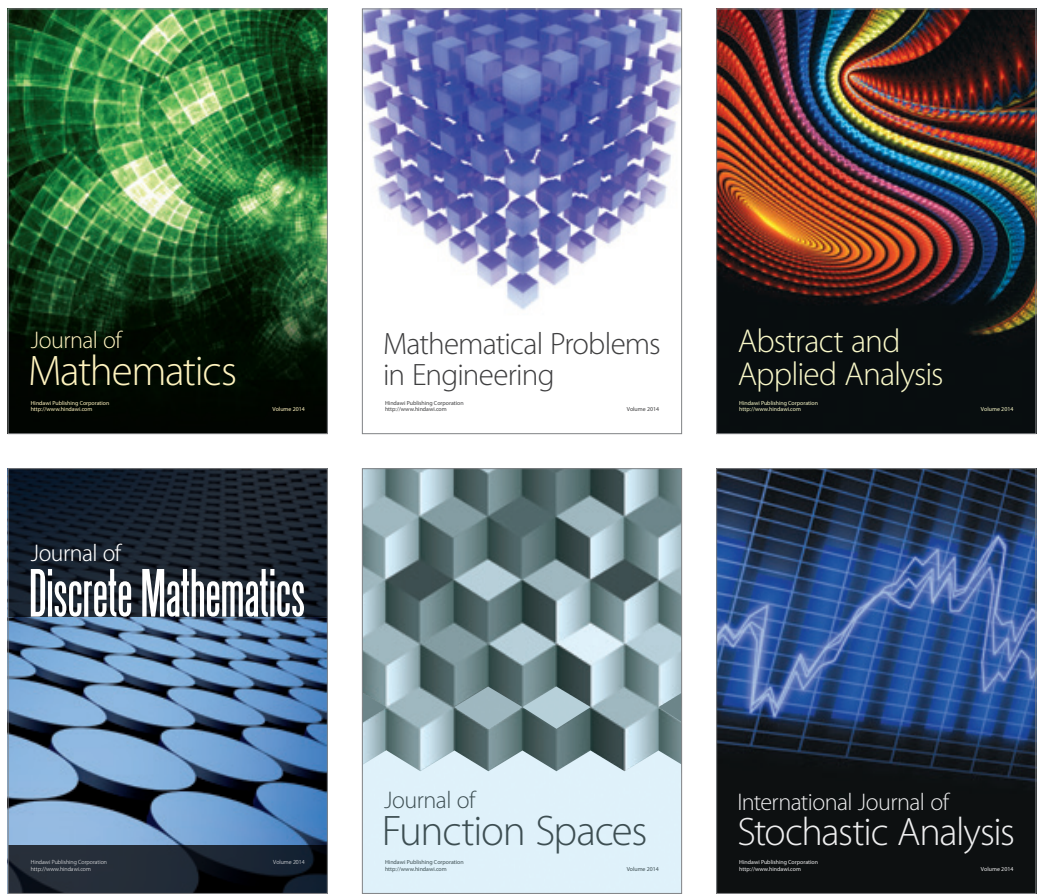

Journal of

Function Spaces

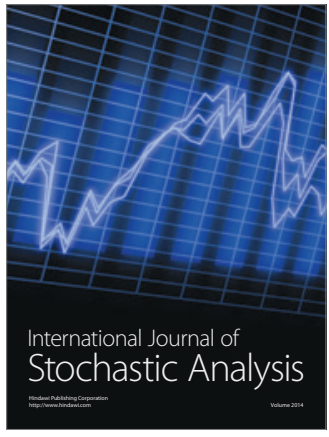

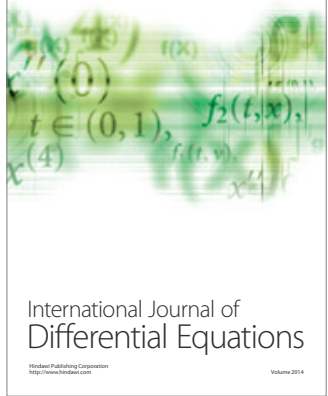
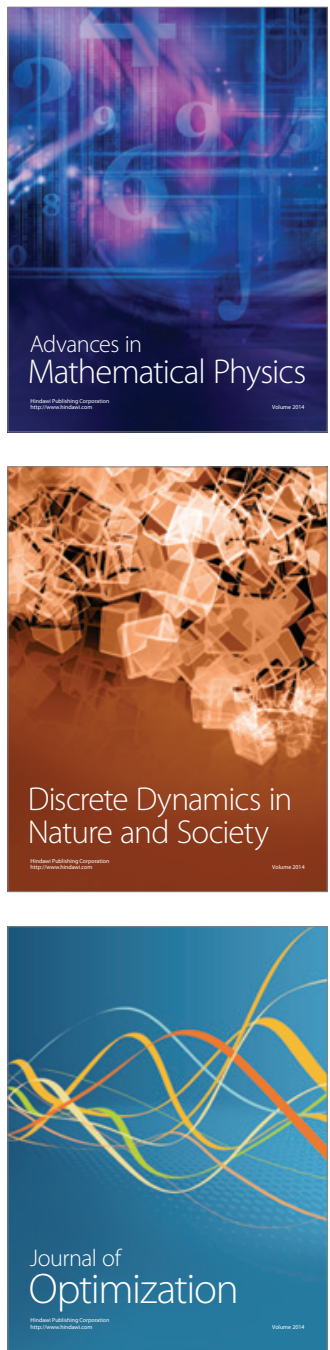